\title{
Guided ultrasonic waves for the monitoring of hidden fatigue crack growth in multi-layer aerospace structures
}

\author{
I. Najarre, E. Kostson, and P. Fromme \\ Department of Mechanical Engineering, University College London, WC1E 7JE, UK
}

\begin{abstract}
Varying loading conditions of aircraft structures result in stress concentration at fastener holes, where multi-layered components are connected, possibly leading to the development of fatigue cracks. The potential of guided ultrasonic waves, propagating along large plate-like structures, for the Structural Health Monitoring (SHM) of aerospace structures has been identified. However, the sensitivity for the detection of small, potentially hidden, defects has to be ascertained. This contribution presents a study of the application of guided ultrasonic waves in multi-layered tensile specimens for the monitoring of fatigue crack growth at fastener holes in the $2^{\text {nd }}$ (bottom) layer of such structures. Fatigue crack growth was monitored optically and the changes in the ultrasonic signal caused by the crack development were quantified. It was shown that hidden fatigue crack detection and monitoring using the low frequency guided waves is possible. The sensitivity and repeatability of the measurements were ascertained, having the potential for fatigue crack growth monitoring at critical and difficult to access fastener locations from a stand-off distance. The robustness of the methodology for practical in-situ ultrasonic monitoring of fatigue crack growth was discussed.
\end{abstract}

Keywords: Guided Ultrasonic Waves, Fatigue Crack, Monitoring, Multi-layer Structure

\section{INTRODUCTION}

Aerospace structures must be tested nondestructively during their service life to detect damage that can occur due to loading and environmental conditions [1]. The adaptation and integration of current nondestructive testing (NDT) techniques for structural health monitoring (SHM) at damage critical locations offers the potential to reduce inspection time and cost. A common maintenance problem is the development of fatigue cracks at fastener holes due to stress concentration. These structures must therefore be regularly inspected to detect fatigue cracks before they have reached a critical length. An ultrasonic-based structural health monitoring method has been developed for real time, in-situ monitoring of fastener hole cracks using an angle beam through transmission technique [2]. Standard bulk wave Ultrasonic Testing (UT) has a proven sensitivity for the detection of small defects, e.g., shear wave angle beam measurements [3]. However, it often necessitates local access and time-consuming scanning of the inspected part [4]. Rayleigh waves have been studied for the detection of surface fatigue cracks [5]. Typically damage detection using Rayleigh waves requires access to the side of the structure containing the defect. The application of guided ultrasonic wave modes in the higher frequency-thickness range has recently been investigated [6]. This type of waves allows for defect detection through the complete thickness of structures over reasonably long distances [6], and can be employed even if local access to the inspected part is not possible [7]. The employed wavelengths are comparable to those commonly used in bulk wave UT, allowing good sensitivity for the detection of small defects [8]. The $\mathrm{S}_{0}$ mode (around $5 \mathrm{MHz} \mathrm{mm}$ ) was used for corrosion detection in aircraft structures [9], and longitudinal modes (above $15 \mathrm{MHz} \mathrm{mm}$ ) were employed for plate inspection [8]. High frequency guided waves were used for in-situ monitoring of fatigue crack growth in tensile, aluminum specimens $[10,11]$. Large areas of plate-like structures can be inspected and monitored from a single, remote access point using low frequency guided ultrasonic waves $[12,13]$. However, the resulting wavelengths are typically significantly larger than in bulk wave UT, thus limiting the sensitivity for the detection of small defects [14, 15]. The interaction of low frequency guided waves with small surface defects in plates has been studied using Finite Element (FE) simulations and experiments $[16,17]$. The propagation of guided ultrasonic waves in bonded components [18] and the interaction with holes in metallic plates has been investigated [19]. The detection of fatigue cracks at fastener holes in plates using low-frequency guided ultrasonic waves was studied [20]. 
The detection of defects in the different layers of the multi-layered aircraft structure is one of the requirements for future SHM systems [21]. Under laboratory conditions and with the presence of a sealant/adhesive layer, small defects in the $2^{\text {nd }}$ layer have been detected [22]. Similar UT techniques for $2^{\text {nd }}$ layer defect detection have been developed [23]. However, $2^{\text {nd }}$ layer defect detection using conventional UT techniques can be problematic if the coupling medium (sealant) between the layers around the fastener hole is inadequate or missing [23,24]. The possibility of fatigue crack detection at fastener holes in multi-layered structures using high frequency guided ultrasonic waves $(5 \mathrm{MHz})$ has been investigated [25], showing that defect detection is possible, but that the detection sensitivity depends on the interface conditions between the layers. The authors also noted that high frequency guided ultrasonic waves are attenuated, if a material, such as an adhesive, is present between the metallic layers, making the monitoring of large areas difficult.

Therefore it is important to identify and study low frequency guided ultrasonic wave modes that are insensitive to interface conditions, but offer good sensitivity for defect detection. A flexural mode similar to the $\mathrm{A}_{0}$ mode has energy distributed through the thickness of the multi-layered structure [26, 27], allowing in principle defect detection in all layers. In the frequency range of interest the phase and group velocity of this $\mathrm{A}_{0}$-like mode are insensitive to local thickness or material property variations of the sealant layer [28]. Utilizing such a mode in the low frequency regime could overcome difficulties such as missing sealant and attenuation, offering potential benefits for the inspection and SHM of large parts consisting of multiple layers. However, low frequency guided ultrasonic waves have wavelengths significantly larger than commonly used in bulk wave UT, therefore the sensitivity for the detection of fatigue defects needs to be ascertained [29].

In this contribution fatigue crack growth at a fastener hole in multi layer tensile specimens has been investigated using low frequency guided ultrasonic waves. The monitoring of the ultrasonic signals was performed using a laser interferometer measurement close to the defect location. The scattered field of the guided wave around the hole and fatigue crack was measured to ascertain the sensitivity for the detection of hidden defects in the bottom layer of the structure with single sided access.

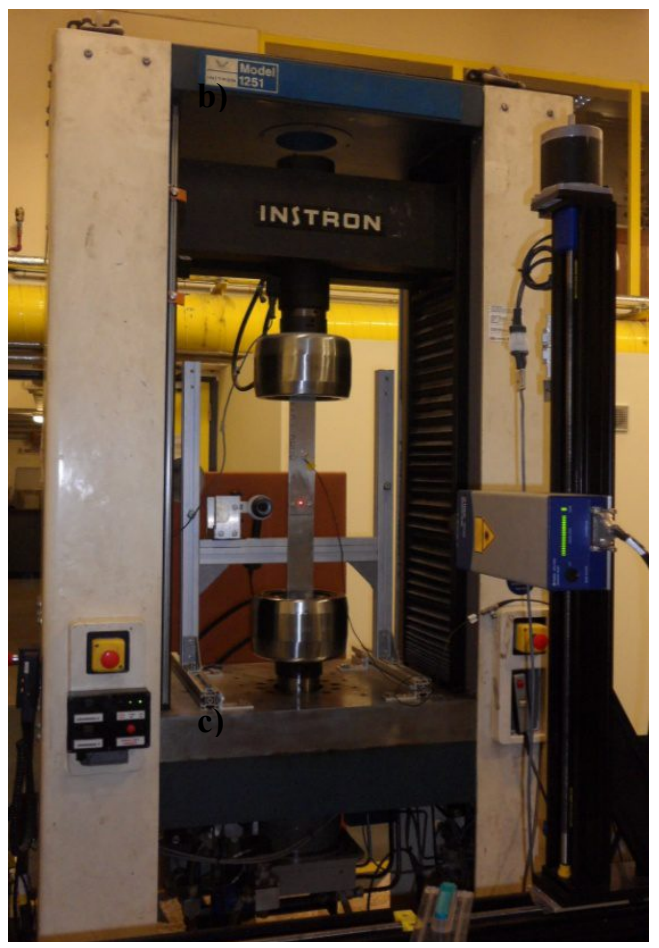

Fig. 1. Experimental setup: multi layer tensile specimen in fatigue testing machine with microscope for optical crack length measurement and laser interferometer. 


\section{EXPERIMENTS}

Fatigue crack growth monitoring at a fastener hole was performed for three multi layer tensile specimens using low frequency guided ultrasonic waves. The specimens $(600 \mathrm{~mm} \times 70 \mathrm{~mm} \times 6.2 \mathrm{~mm})$ consist of two $3 \mathrm{~mm}$ thick aluminum alloy (2014-T6) plate strips, adhesively bonded with a $0.2 \mathrm{~mm}$ thick adhesive layer (HYSOL-9394 EA). A 1/4 inch diameter hole $\left(r_{0}=3.17 \mathrm{~mm}\right)$ was drilled on the center line $290 \mathrm{~mm}$ from the specimen end. For the fatigue experiments the specimens were subjected to cyclic tensile loading in a servo-hydraulic testing machine (Fig. 1). The loading axis was parallel to the center line of the specimen. A maximum load of $54 \mathrm{kN}$ was selected so that the maximum stress in the vicinity of the fastener hole reached about $95 \%$ of the yield limit (stress concentration factor $K_{t} \approx 3.1$ ). The corresponding maximum nominal stress is approximately $125 \mathrm{~N} / \mathrm{mm}^{2}$. The cyclic loading was performed with a stress ratio of $R=0.1$ and cycling frequency of $7 \mathrm{~Hz}$. The crack initiation is expected to occur at the hole boundary at an angle of approximately $90^{\circ}$ relative to the loading axis. A small starter notch, approximately $0.2 \mathrm{~mm}$ long was made at the corner of the hole with the surface of the bottom layer to control the crack location. During fatigue testing the crack initially grew quarter-elliptically from the starter notch before developing into a through-thickness crack in the bottom aluminum layer. No fatigue crack was observed in the top aluminum layer. The cyclic loading was stopped every 1'000 cycles and the maximum tensile load was applied to avoid crack closure. The crack length on the specimen bottom surface was measured optically using a microscope and the ultrasonic monitoring measurements were performed.

A piezoelectric disc (Ferroperm Pz 27, diameter $5 \mathrm{~mm}$, thickness $2 \mathrm{~mm}$ ) with a brass backing mass (diameter $5 \mathrm{~mm}$, thickness $6 \mathrm{~mm}$ ) was permanently bonded onto the top surface of the tensile multi layer specimen using two-component epoxy glue $110 \mathrm{~mm}$ from the fastener hole. The out-of-plane forcing was chosen to excite a bending mode similar to the $\mathrm{A}_{0}$ mode in a single layer plate [27]. The excitation signal consisted of a 5 cycle, $100 \mathrm{kHz}$ tone burst in a Hanning window and had narrow bandwidth. The signal was generated using an arbitrary function generator, amplified and applied to the transducer. The wavelength of the excited mode in the multi layer structure is about $18 \mathrm{~mm}$. The amplitude of the guided ultrasonic wave pulse was measured using a heterodyne laser interferometer on the top surface opposite the crack location in the bottom layer. The demodulated output signal obtained from the interferometer was band-pass filtered around the center frequency and averaged 20 times in an oscilloscope. Two types of measurements were performed. The scattered field around the hole (and crack) was measured before and after the cyclic loading to obtain a fatigue crack. The laser interferometer was moved parallel to the specimen surface using a scanning rig on a circular measurement grid (angular resolution: 5 degrees, radial resolution: $0.5 \mathrm{~mm}$ ) from the hole boundary to a maximum radius of $10 \mathrm{~mm}$. During the fatigue cycling the laser measurement spot was kept in one location approximately $1 \mathrm{~mm}$ sideways from the hole boundary and $2 \mathrm{~mm}$ in front of the expected fatigue crack location on the hole side of the starter notch. The time traces were evaluated to obtain the maximum amplitude of the envelope of the guided wave pulse using the Hilbert transform in Matlab.
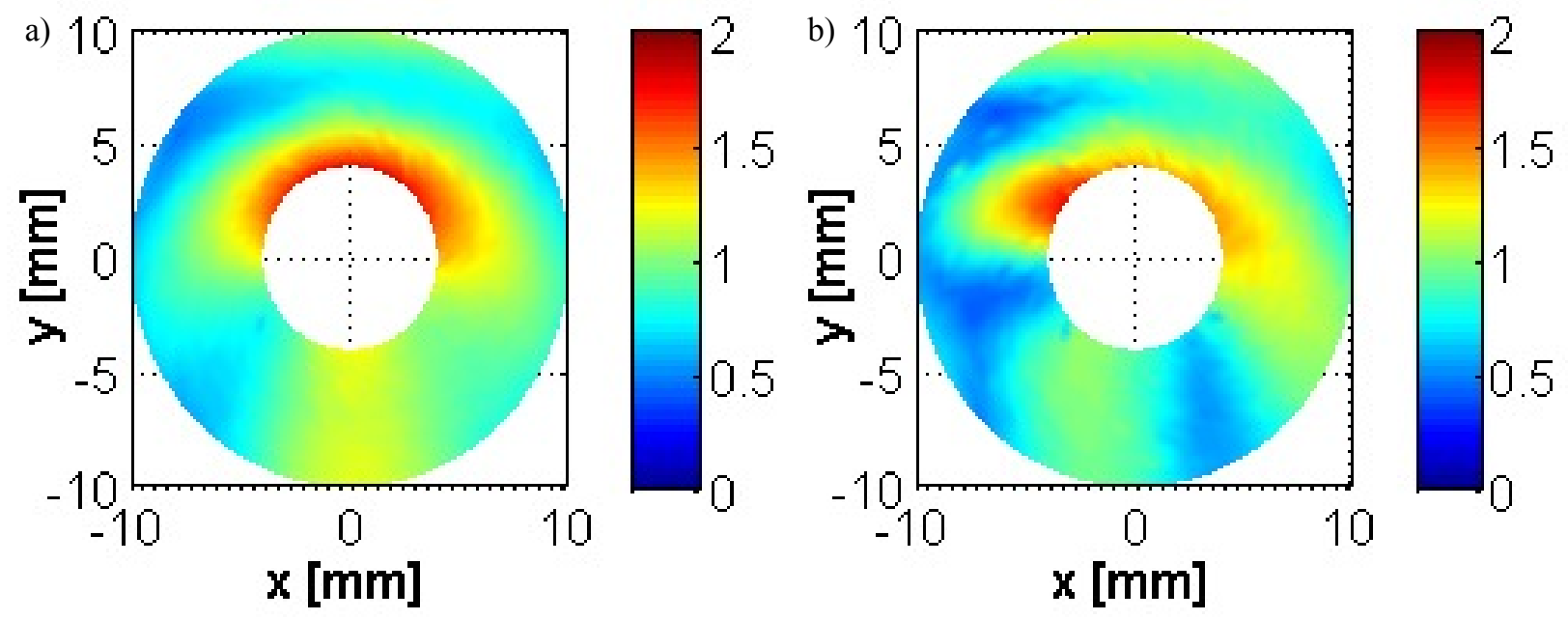

Fig. 2. Measured scattered field, maximum amplitude of guided wave pulse $\left(f_{0}=100 \mathrm{kHz}\right)$ measured using laser interferometer on top surface for one tensile specimen: a) undamaged hole; b) hole with $8.5 \mathrm{~mm}$ long fatigue crack on left hand side in bottom aluminum layer. 


\section{GUIDED WAVE SCATTERING AT A FASTENER HOLE WITH A FATIGUE CRACK}

The scattered field of the guided wave around the fastener hole was measured as described above before the start of the cyclic loading and with a $8.5 \mathrm{~mm}$ long fatigue crack visible on the surface of the bottom layer. It was verified from a visual inspection in the fastener hole that the fatigue crack had grown through the thickness of the bottom aluminum layer. Based on previous experience it has to be assumed that the adhesive layer close to the fatigue crack was damaged during the cyclic loading. No fatigue cracking was observed in the top aluminum layer on which the laser measurement was performed.

Shown in Fig. 2a is the scattered field measured using the laser interferometer on a circular grid around the undamaged fastener hole. For each measurement point the maximum amplitude of the envelope of the guided wave pulse was extracted using the Hilbert transform. These are displayed in Fig. 2 color-coded with red corresponding to high amplitude and blue to low amplitude. For the undamaged hole a symmetric scattering pattern can be observed. The high amplitude (red) at the top of the hole boundary results from the reflection of the guided wave incident from the top at the free boundary. The amplitude variation around the hole arises due to the constructive and destructive interference of the incident and scattered waves around the hole. A significant change in the scattered field can be observed in Fig. $2 b$ due to the fatigue crack on the left side of the hole in the bottom aluminum layer. The scattered field is not symmetric anymore and an increase in amplitude can be observed before the fatigue crack. Reduced amplitude of the guided wave behind the fatigue crack location is due to the scattering of the incident guided wave.

\section{GUIDED WAVE MONITORING OF FATIGUE CRACK GROWTH}

Based on the evaluation of the scattered guided wave field it was decided to place the laser measurement spot during the fatigue cycling just in front of the expected fatigue crack location in the bottom layer. Cyclic loading of three multi layer tensile specimens was carried out as described above. For all three specimens the fatigue crack was first observed visually between $15^{\prime} 000$ and $20^{\prime} 000$ cycles. The optically measured crack length on the bottom surface is shown for the 3 specimens in Fig. 3. From the starter notch the crack grew with quarter elliptical shape in the bottom layer. Reaching the thickness of the bottom layer $(3 \mathrm{~mm})$, the crack continued to grow in length as a through crack in this layer. No cracking of the top layer was observed. Similar crack growth rates can be observed in Fig. 3 for the 3 specimens even though crack initiation varied slightly.

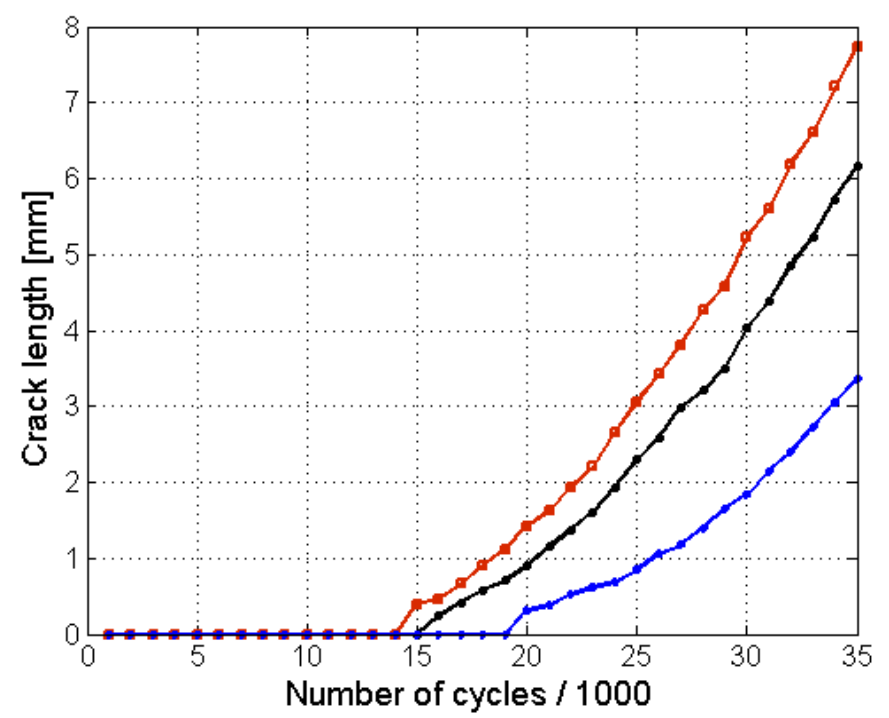

Fig. 3. Optically measured crack length plotted against number of cycles for three fatigue tests of multi-layer tensile specimens. 


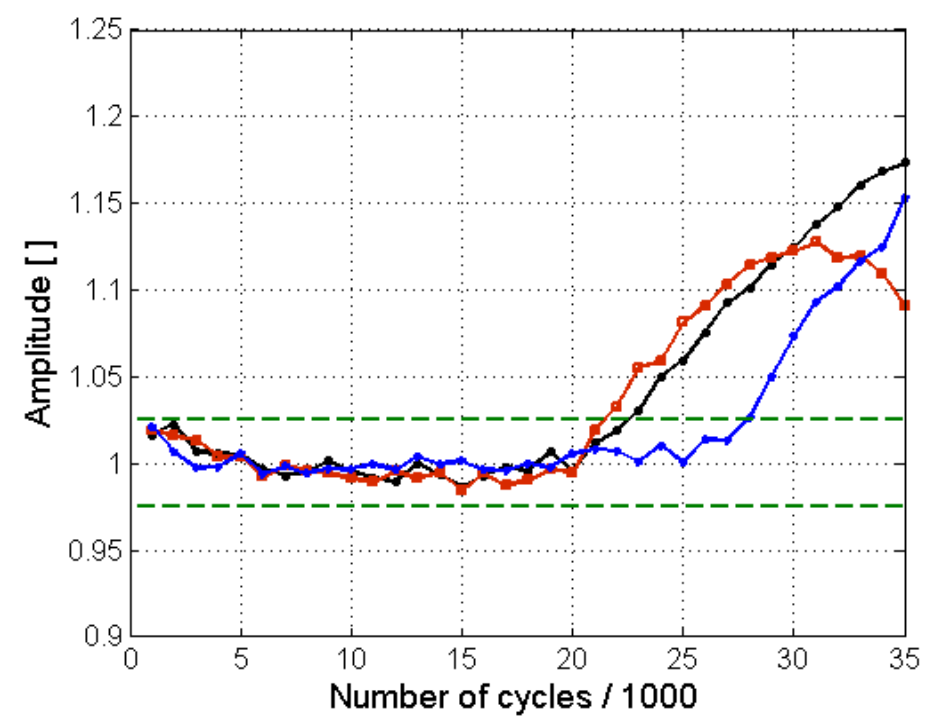

Fig. 4. Amplitude ratio of low frequency guided ultrasonic wave pulses against number of cycles for three fatigue tests of multi-layer tensile specimens (black, red, blue), $f_{0}=100 \mathrm{kHz}$; green dashed line: $2.5 \%$ amplitude variation.

Shown in Fig. 4 are the maximum amplitudes of the guided wave pulses during the fatigue crack growth. The cyclic loading was stopped every 1'000 cycles and the maximum tensile load was applied to avoid crack closure. The monitored amplitude was normalized for each specimen with respect to the amplitude measured with no crack present. A small drop of the amplitude during the first 5'000 cycles can be observed with rather constant amplitude until approximately $20^{\prime} 000$ cycles for all specimens. The maximum variation before the crack was observed visually was quantified as less than $2.5 \%$ for all specimens and is shown as the dashed green line in Fig. 4. An increase in the measured amplitude above that level can be seen at $22^{\prime} 000,23^{\prime} 000$, and $28^{\prime} 000$ cycles respectively for the 3 specimens. Comparing to Fig. 3 this corresponds to a fatigue crack length of between $1 \mathrm{~mm}$ and $2 \mathrm{~mm}$. In order to evaluate this, the observed amplitude ratio was plotted against the crack length in Fig. 5. The amplitude of the guided wave at the monitoring location in front of the crack increases as expected with increasing crack length. For a $5 \mathrm{~mm}$ long crack through the bottom layer the average measured amplitude increase for the three specimens was about $17 \%$. This measured change in amplitude of the guided ultrasonic wave is significantly larger than the variation observed during the fatigue experiments of less than $2.5 \%$.

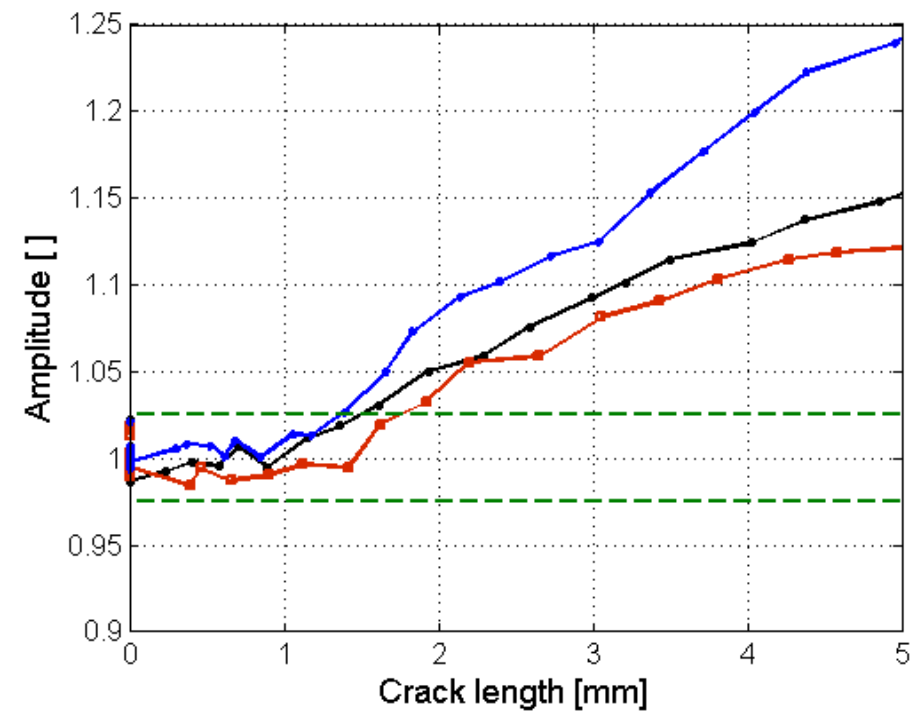

Fig. 5. Amplitude ratio of low frequency guided ultrasonic wave pulses against optically measured crack length for three fatigue tests of multi-layer tensile specimens (black, red, blue), $f_{0}=100 \mathrm{kHz}$; green dashed line: $2.5 \%$ amp. variation. 


\section{CONCLUSIONS}

This contribution investigated the possibility of using low frequency guided ultrasonic waves for the detection and monitoring of hidden fatigue crack growth at fastener holes in multi layer tensile specimens. The ultrasonic wave was excited using a piezoelectric transducer and measured using a laser interferometer on the opposite layer of the fatigue crack location. The changes in the guided ultrasonic wave signal were quantified on the basis of the amplitude ratio. The resulting increase in amplitude was repeatable between the three measured specimens. A significant amplitude increase of about $17 \%$ had occurred for a $5 \mathrm{~mm}$ long fatigue crack, significantly larger than the observed amplitude variations of less than $2.5 \%$ during the fatigue cycling. For cracks larger than about $2 \mathrm{~mm}$ the amplitude ratio correlates well with the optically measured crack area. This allows in principle for the detection of bottom layer fatigue cracks from guided ultrasonic wave measurements on the top layer in multi layer structures. In order to employ this technique for future aircraft structural health monitoring (SHM) applications, a number of steps would have to be implemented to ascertain the realistic application, reliability, and robustness of this technique for large multi-layered structures.

\section{ACKNOWLEDGEMENTS}

This work was supported in part by grant EP/D065011/1 from the UK Engineering and Physical Sciences Research Council (EPSRC).

\section{REFERENCES}

[1] Dalton, R.P., Cawley, P. and Lowe, M.J.S., "The potential of guided waves for monitoring large areas of metallic aircraft fuselage structures," J. Nondestr. Eval. 20, 29-46 (2001).

[2] Michaels, J.E., Michaels, T.E. and Mi, B., "An ultrasonic angle beam method for in situ sizing of fastener hole cracks," J. Nondestruct. Eval. 25, 3-16 (2006).

[3] Cobb, A.C., Michaels, J.E. and Michaels, T.E., "An automated time-frequency approach for ultrasonic monitoring of fastener holes," NDT \& E Int. 40, 525-536 (2007).

[4] Alleyne, D.N. and Cawley, P., "The interaction of Lamb waves with defects," IEEE Trans. Ultrason. Ferroelectr. Freq. Control 39, 381-397 (1992).

[5] Cook, D.A. and Berthelot, Y.H., "Detection of small surface-breaking cracks in steel using scattering of Rayleigh waves," NDT \& E Int. 34, 483-492 (2001).

[6] Masserey, B. and Fromme, P., "On the reflection of coupled Rayleigh-like waves at surface defects in plates," J. Acoust. Soc. Am. 123, 88-98 (2008).

[7] Masserey, B. and Fromme, P., "Surface defect detection in stiffened plate structures using Rayleigh-like wave," NDT\&E Int. 42(6), 564-572 (2009).

[8] Greve, D.W., Zheng, P. and Oppenheim, I.J., "The transition from Lamb waves to longitudinal waves in plates," Smart Mater. Struct. 17, 035029 (2008).

[9] Terrien, N., Osmont, D., Royer, D., Lepoutre, F. and Déom, A., "A combined finite element and modal decomposition method to study the interaction of Lamb modes with micro-defects," Ultrasonics 46, 47-78 (2007).

[10] Masserey, B. and Fromme, P., "In-situ Monitoring of Fatigue Crack Growth at Fastener Holes Using Rayleigh-like Waves" in Rev. Prog. QNDE 27, ed. by D.O. Thompson and D.E. Chimenti, AIP Conference Proceedings 975, New York, pp. 1484-1491 (2008).

[11] Masserey, B. and Fromme, P., "Fatigue Crack Growth Monitoring using High Frequency Guided Waves," Struct. Health Monit. 12, 484-493 (2013).

[12] Fromme, P., Wilcox, P.D., Lowe, M.J.S. and Cawley, P., "On the development and testing of a guided ultrasonic wave array for structural integrity monitoring," IEEE Trans. Ultrason. Ferroelectr. Freq. Control 53, 777-785 (2006).

[13] Fromme, P., "Monitoring of Plate Structures Using Guided Ultrasonic Waves," in Rev. Prog. QNDE 27, ed. by D.O. Thompson and D.E. Chimenti, AIP Conference Proceedings 975, New York, 78-85 (2008).

[14] Castaings, M., Le Clezio, E. and Hosten, B., "Modal decomposition method for modeling the interaction of Lamb waves with cracks," J. Acoust. Soc. Am. 112, 2567-2582 (2002).

[15] Fromme, P., "Health Monitoring of Plate Structures using Guided Waves," Proceedings of SPIE 6935, 69350W (2008). 
[16] Lowe, M.J.S., Cawley, P., Kao, J.-Y. and Diligent, O., "The low frequency reflection characteristics of the fundamental antisymmetric Lamb wave $\mathrm{a}_{0}$ from a rectangular notch in a plate," J. Acoust. Soc. Am. 112, 2612-2622 (2002).

[17] Fromme, P., Wilcox, P.D., Lowe, M., and Cawley, P., "On the Scattering and Mode Conversion of the A0 Lamb Wave Mode at Circular Defects in Plates," in Rev. Prog. QNDE 23, ed. by D.O. Thompson and D.E. Chimenti, AIP Conference Proceedings 700, New York, 142-149 (2004).

[18] Fan, Z., Castaings, M., Lowe, M.J.S., Biateau, C., and Fromme, P., "Feature-guided waves for monitoring adhesive shear modulus in bonded stiffeners," NDT\&E International 54(1), 96-102 (2013).

[19] Fromme, P. and Sayir, M.B., "Measurement of the scattering of a Lamb wave by a through hole in a plate," J. Acoust. Soc. Am. 111, 1165-1170 (2002).

[20] Fromme, P. and Sayir, M.B., "Detection of cracks at rivet holes using guided waves," Ultrasonics 40(1-8), 199-203 (2002).

[21] Smith, C.D., "Federal Aviation Administration Aircraft Inspection Research and Development Programs," Proceedings of SPIE 2945, 200-209 (1996).

[22] Lindgren, E., Judd, D., Concordia, M., Mandeville, J., Aldrin, J.C., Spencer, F., Fritz, D., Pratt, E., Waldbusser, R., and Mullis, R.T. "Validation and deployment of automated ultrasonic inspections for the C-130 center wing," ASIP Conference Savanna, Georgia (2004).

[23] Smith, R.A., Edgar, D., Jones, L.D. and Percivall, D.M. "An ultrasonic solution for second- layer crack detection," Insight 47, 81-84 (2005).

[24] Lindgren, E., Knopp, J.S., Aldrin, J.C., Steffes, G.J. and Buynak, C.F., “Aging aircraft NDE: capabilities, challenges and opportunities," in Rev. Prog. QNDE 26, ed. by D.O. Thompson and D.E. Chimenti, AIP Conference Proceedings 894, 1731-1738 (2007).

[25] Lindgren, E., Aldrin, J.C., Jata, K., Scholes, B. and Knopp, J. "Ultrasonic plate waves for fatigue crack detection in multi-layered metallic structures" Proceedings of SPIE 6532, 53207 (2007).

[26] Rokhlin, S. I. "Lamb wave interaction with lap-shear adhesive joints: theory and experiment," J. Acoust. Soc. Am. 89, 2758-2765 (1991).

[27] Kostson, E. and Fromme, P., "Fatigue crack growth monitoring in multi-layered structures using guided ultrasonic waves," Journal of Physics: Conference Series 195, 012003 (2009).

[28] Lowe, M.J.S. and Cawley, P. "The applicability of plate wave techniques for the inspection of adhesive and diffusion bonded joints," J. Nondestr. Eval. 13, 185-200 (1994).

[29] Kostson, E. and Fromme, P. "Defect detection in multi-layered structures using guided ultrasonic waves," in Rev. Prog. QNDE 28, ed. by D.O. Thompson and D.E. Chimenti, AIP Conference Proceedings 1096, 209-216 (2009). 